\title{
Chiral Recognition in the Gas Phase: Mass Spectrometric Studies of Diastereomeric Cobalt Complexes
}

\author{
Thuy T. Dang, Steven F. Pedersen, and Julie A. Leary \\ Department of Chemistry, University of California, Berkeley, California, USA
}

Results of mass analyzed ion kinetic energy (MIKE) spectra and kinetic energy release (KER) measurements of diastereomeric octahedral cobalt complexes indicate that these diastereomers can be distinguished in the gas phase. Four alkyl tartrate esters were complexed to cobalt trisacetylacetonate (Co(acac) $)_{3}$ ) in the presence of a chiral auxiliary, RR and SS threo hydrobenzoin. Different KER values of the product ion generated from [Co(acac) $2 / \mathrm{D}$ - or L-diisopropyl tartrate] ${ }^{+}$reflect differences in the precursor ion structure. The dissociation pathway resulting in this product ion is believed to arise via a hydride transfer from the acetylacetonate ligand to the metal center with subsequent loss of neutral organic species. It has been established that two conditions are necessary for observation of chiral recognition in this system; (1) the cobalt complex must be octahedral and (2) a chemical kinetic resolving agent must be present during formation of the complex. (J Am Soc Mass Spectront 1994, 5, 452-459)

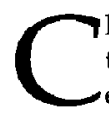

hirality plays a crucial rolc in biochemical systems. While one enantiomer of a molecule may exhibit biological activity, the other may be totally inactive. In other cases, one enantiomer may be a potent pharmaceutical while the other may cause serious side effects. The increasing need for optically pure compounds has made their synthesis an important focus of current research in both academic and industrial laboratories. Analytical chemists have aided this surge in enantioselective synthesis by developing new chromatographic techniques that allow separation of enantiomeric pairs in order to determine the enantiomeric purity of a given compound (e.g., chiral gas chromatography (GC) [1] and high-performance liquid chromatography (HPLC) columns [2]). However, there has been very little accomplished in the area of mass spectrometry with regards to chiral recognition.

It is often assumed that mass spectrometry is not capable of analyzing for chirality since it performs its analysis by mass. However, by using metal-coordinated chiral auxiliaries (either preattached or added directly to the sample), diastereomeric adducts of compounds of interest can be formed. Analysis of the tandem mass spectra of the different diastereomers can possibly lead to some predictable trends that should ultimately allow the assignment of the absolute stereochemistry of certain functional groups in an unknown

Address reprint requests to Professor Julie A. Leary, Department of Chemistry, University of California, Berkeley, CA 94720.

(c) 1994 American Society for Mass Spectrometry $1044-0305 / 94 / \$ 7.00$ compound. Since mass spectrometry methods generally require microgram quantities of the analyte, applications of such methodology would be particularly useful in areas where only small amounts of material are available; for example, natural products isolation studies.

The first study of gas phase chiral recognition using mass spectrometry was described by Fales and Wright in 1977 [3]. Using chemical ionization mass spectrometry (CI/MS) and deuterium labeling experiments, they observed that chirality is preserved in a portion of the population of enantiomeric dimer cluster ions ([2M + $\mathrm{H}^{+}$) of some tartrates as evidenced by differences in abundance. A mass spectrometric review on stereochemical effects was published shortly after [4]. Later, others also investigated hetero- and homochiral dimer clusters by CI/MS and also observed chirospecificity in the dimer clusters as indicated by differences in ion abundance $[5,6]$. More recently, our group [7] and that of Sawada et al. [8] have investigated the possibility of chiral recognition using fast atom bombardment mass spectrometry ( $\mathrm{FAB} / \mathrm{MS}$ ). In the latter case, enantioselectivity was characterized by the relative peak intensity method whereas in the former, kinetic energy release (KER) measurements were used to discriminate between lithium coordinated enantiomeric diols.

In this study we have combined various optically active alkyl tartrate esters (1), with RR- or SS-threohydrobenzoin (2) (THB), and a racemic mixture of 
cobalt trisacetylacetonate (3) ( $\left.\mathrm{Co}(\mathrm{acac})_{3}\right)$. These solutions were analyzed by FAB/MS and the various ions detected were then chosen for subsequent mass ion kinetic energy spectrometry (MIKES) and KER studies. This is the first study in which diastereomeric metal complexes were analyzed by mass spectrometry and statistically significant differences observed in the KER values. The ultimate goal of this project is to develop reproducible mass spectrometric methods to establish the absolute configuration of stereogenic centers in organic molecules.<smiles>O=C(O)C(=O)C(O)C(=O)O</smiles>

Dialkyl tartrate (D or L) 1

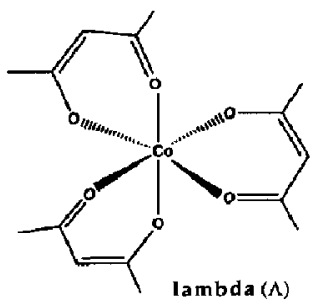

Cobalt-trisacetylacetonate (Co(acac) 3<smiles>OC(c1ccccc1)C(O)c1ccccc1</smiles>

threo-Hydrobenzoin (THB) (R,R or $\mathbf{S}, \mathbf{S})$ $\underline{\mathbf{2}}$

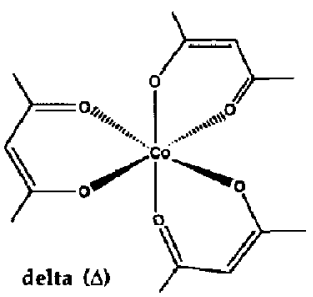

\section{Experimental}

\section{Instrumentation}

Mass spectra were obtained using a VG ZAB2-EQ mass spectrometer (VG Analytical, Manchester, U.K.) of $B E O Q$ geometry ( $o$ is an rf only octapole collision cell fabricated in our laboratory and replaces the conventional quadrupole cell in this particular instrument). This instrument is equipped with three reaction regions. The first reaction region is for $\mathrm{B} / \mathrm{E}$ linked scanning, the second reaction region is used for MIKES scanning, and the third reaction region (octapole cell) is for low energy collision-induced dissociation (CID).

The MIKES studies were carried out in the second reaction region between the magnet (B) and the electric sector (ESA) and spectra were obtained using $8 \mathrm{kV}$ accelerating voltage. The MIKES cell was floated at $+2.5 \mathrm{kV}$ to eliminate artifact ions. The resolution measured at the second detector was 1:1000. The precursor ion was transmitted into the MIKES cell and allowed to undergo unimolecular decomposition at a pressure of $1 \times 10^{-8}$ torr (no gas was added). The product ion spectra were generated by scanning the ESA while setting the magnet to pass only the mass of the precursor ion.

The KER values were calculated according to eq 1 below [9]

$$
\operatorname{KER}(\mathrm{meV})=\frac{\mathrm{y}^{2} \mathrm{~m}_{1}^{2} \mathrm{eV}}{16 \mathrm{~m}_{2} \mathrm{~m}_{3}}\left(\frac{\Delta \mathrm{E}}{\mathrm{E}}\right)^{2}
$$

where $m_{1}$ is the mass of the precursor ion; $m_{2}$ is the mass of the product ion; $m_{3}$ is the mass of the neutral loss; $\mathrm{y}$ is the charge; $\mathrm{eV}=\mathrm{E}=8000 \mathrm{~V} ; \Delta \mathrm{E}=\left(\Delta \mathrm{E}_{50 \%}^{2}\right.$ $\left.-\Delta \mathrm{Em}_{1}^{2}\right)^{1 / 2} ; \Delta \mathrm{E}_{50 \%}=$ width (in volts) of the product ion peak at half height; and $\Delta E \mathrm{~m}_{1}=$ width (in volts) of the precursor ion peak at half height. Several measurements were made manually and the values compared with the computer generated results. Since both the manual and computer output were in excellent agreement, all subsequent values were measured using the computer program supplied with the data system software.

High resolution $F A B / M S$ was performed on all of the precursor ions prior to MIKES studies in order to determine if isobaric ions were present. At a resolution of $1: 10,000$ only $m / z 491$ was a doublet. When peak matching the doublet against $m / z 460.1356$ (the protonated trimer of NBA), the doublet was found to correspond to $\left[\mathrm{Co}^{+3}(\mathrm{acac})_{2} / \mathrm{DIPT}\right]^{+}$and $\left[\mathrm{Na}^{+} /(\mathrm{DIPT})_{2}\right]^{+}$ ions (see Results and Discussion section).

\section{Chemicals and Solutions}

The cobalt trisacetylacetonate $\left(\mathrm{Co}(\mathrm{acac})_{3}\right) /$ diol solutions were prepared by combining (1) $1 \mu \mathrm{l}$ of $\mathrm{Co}(\mathrm{acac})_{3}$ solution (0.05 M in methanol), (2) $2 \mu \mathrm{l}$ of either RR- or SS-THB (0.5 M in methanol), (3) $1 \mu 1$ of either D- or L-tartrate ( $1 \mathrm{M}$ in methanol) where the tartrates included dimethyl tartrate (DMT), diethyl tartrate (DE'T), diisopropyl tartrate (DIPT), or dibutyl tartrate (DBT), and (4) $4 \mu \mathrm{l}$ of neat m-nitrobenzyl alcohol (NBA) as the fast-atom bombardment (FAB) matrix. Approximately $2 \mu$ l of the mixture was deposited on the FAB probe tip and ionized using $20 \mathrm{kV}$ cesium ion bombardment with approximately $1.0 \mu \mathrm{A}$ current.

Deuterium labeling experiments were carried out by adding $\mathrm{D}_{2} \mathrm{O}$ to the stock tartrate and NBA solutions and allowing the solutions to sit overnight. Details of the labeling experiment are discussed in our previous. work [10].

The cobalt chloride $\left(\mathrm{CoCl}_{2}\right)$ solutions were prepared by combining $1 \mu \mathrm{l}$ of $\mathrm{CoCl}_{2}\left(1 \mathrm{M}\right.$ in $\left.\mathrm{H}_{2} \mathrm{O}\right), 2 \mu \mathrm{l}$ of either RR- or SS-THB ( $0.5 \mathrm{M}$ in methanol), $1 \mu \mathrm{l}$ of $\mathrm{D}$ - or L-DIPT (1 M in methanol), and $4 \mu 1$ of neat NBA. Approximately $2 \mu \mathrm{l}$ of the mixture solution was deposited on the $\mathrm{FAB}$ probe tip.

The $\mathrm{Co}\left(\mathrm{acac}_{3}, \mathrm{CoCl}_{2}, \mathrm{~L}-\mathrm{DMT}\right.$, D-DMT, L-DET, DDET, L-DIPT, D-DIPT, L-DBT, RR-THB, SS-THB, and NBA were purchased from Aldrich. D-DBT was purchased from Eastman Kodak. All of the chemicals were used as purchased without additional purification.

\section{Results and Discussion}

At this point it is important to define several stereochemical terms and oxidation states/charge states of 
the organic ligands. The arrangement of the three acetylacetonate (acac) ligands about cobalt produces a chiral compound which can exist as individual enantiomers, 3, or as a racemic mixture. When one of the acac ligands of both the lambda $(\Lambda)$ and delta $(\Delta)$ enantiomers is replaced with a chiral tartrate molecule, for example D-diisopropyl tartrate (1), two stereoisomers are formed. More specifically, these stereoisomers are diastereomers. The relationship between these diastereomers and enantiomers is depicted schematically below. The $\Delta$ and $\Lambda$ refer to the two enantiomers of $\mathrm{Co}(\mathrm{acac})_{3}$ and the $\mathrm{D}$ and $\mathrm{L}$ refer to the two enantiomers of the individual alkyl tartrates. The numbers, 1 and 3, refer to the compound structures. According to this schematic, the ion Co(acac) $2 / D$-DIPT (either the $\Delta$ or $\Lambda$ forms) (4) is a diastereomer. Both of these diastereomers would of course have its corresponding enantiomers.

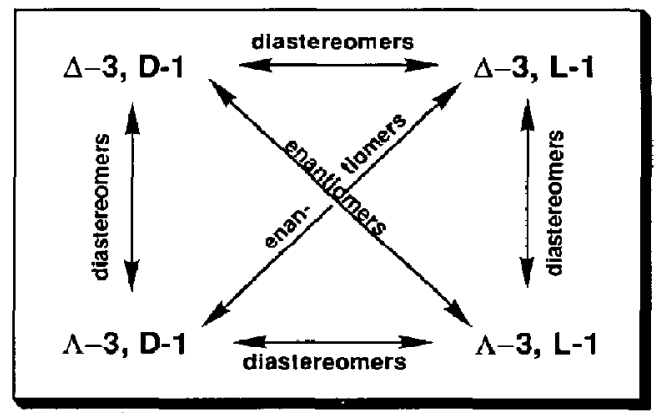

All of the octahedral complexes discussed contain a six-coordinate cobalt in the +3 oxidation state unless specified otherwise. For example, all the alkyl tartrates and the THB are neutral ligands and when coordinated to cobalt carry no charge. The acac ligands are each -1 with respect to cobalt. Thus for compound 3, each acac ligand is -1 and the cobalt is in $a+3$ oxidation state resulting in a neutral complex. Compound 4, which is one of the ions detected in the mass spectrometry experiments is +1 overall; for example, each acac ligand is -1 , the DIPT is neutral, and therefore cobalt must be +3 in order for the complex to be detected as a positively charged ion with the correct corresponding mass.

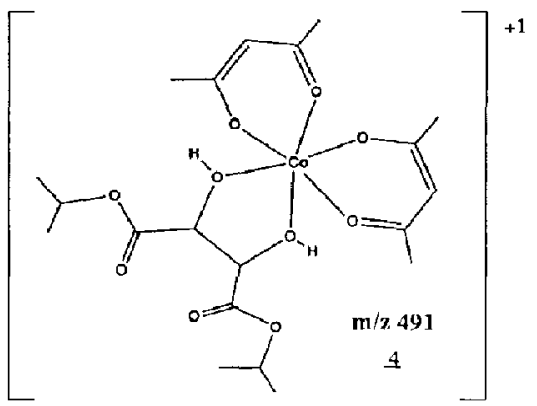

\section{Low and High Resolution FAB Experiments}

The first set of complexes studied were those of DMT, DET, DIPT, and DBT with Co(acac) ${ }_{3}$. For each enantiomer of tartrate, two low resolution FAB spectra were collected. For example, for D- and L-DIPT, four solutions were analyzed: (1) $\left.\mathrm{Co}_{(\mathrm{acac}}\right)_{3}+\mathrm{RR}-\mathrm{THB}+$ D-DIPT, (2) Co(acac) C $_{3}+$ SS-THB + D-DIPT, (3) $\mathrm{Cu}(\mathrm{acac})_{3}+\mathrm{RR}-\mathrm{THB}+\mathrm{L}-\mathrm{DIPT}$, and (4) $\mathrm{Co}(\mathrm{acac})_{3}+$ SS-THB + L-DIPT. Thus 16 low resolution FAB spectra were collected for the four tartrates studied. Figure 1 is a representative spectrum collected for the Co(acac) + SS-THB + L-DIPT sample and Table 1 lists the compositions of the major ions detected. In all 16 cases, the ion representing $\left[\mathrm{Co}^{+3}(\mathrm{acac})_{2} / \mathrm{T}\right]^{\prime}$ (where $\mathrm{T}=\mathrm{DMT}$, DET, DIPT, or DBT) was formed (this is the ion which was further investigated by KER measurements and is discussed below).

The spectrum in Figure 1 reveals the presence of various sodium complexes and so a concern arose as to the possibility of isobaric ion formation. Thus it became obvious that high resolution mass measurements would have to be made in order to determine if such ions were present prior to the MIKES study. The instrument was tuned to a resolution of 1:10,000 and all precursor ions for all the complexes under investigation were measured prior to any further studies. With the exception of the cluster at $m / z \quad 491$ for the $\left[\mathrm{Co}^{+3}(\mathrm{acac})_{2} / \mathrm{DIPT}\right]^{+}$complex, there were no doublets found at this resolution for any of the complexes. The ion at $m / z 491$, however, was found to represent both $\left[\mathrm{Co}^{+3}(\mathrm{acac})_{2} / \mathrm{DIPT}\right]^{+}$and $\left[\mathrm{Na}^{+} /(\mathrm{DIPT})_{2}\right]^{+}$, the exact masses of which differ by only 0.08 atomic mass units (AMU). The experimentally measured masses and theoretical values are provided in Table 2 .

MIKE spectra were recorded for both isobars by first making the $\left[\mathrm{Na}^{+} /(\mathrm{DIPT})_{2}\right]^{+}$complex in the absence of $\left.\mathrm{Co}_{\text {(acac }}\right)_{3}$ and collecting the data for the sodium complex only. Comparing the results obtained with and without the Co(acac) 3 indicated that the sodium complex did not decompose to the same ions observed for the cobalt complex and therefore the kinetic energy release measurements made from the unimolecular decomposition of $\left[\mathrm{Co}^{+3}(\mathrm{acac})_{2} / \mathrm{DIPT}\right]^{+}$ $(\mathrm{m} / z$ 491) were because of the cobalt complex only (this is discussed in further detail below).

\section{KER Measurements}

MIKE spectra were collected for all the tartrate complexes and Table 3 lists the precursor and product ions detected for each complex. Both enantiomers of each $\left[\mathrm{Co}^{13}(\mathrm{acac})_{2} / \mathrm{T}\right]^{+}$complex produced the same ions upon dissociation. The diastereomeric complexes $\left[\mathrm{Co}^{+3}\left(\mathrm{acac}_{2} / \mathrm{D}-\mathrm{DIPT}\right]^{+}\right.$and $\left[\mathrm{Co}^{+3}(\mathrm{acac})_{2} / \mathrm{L}-\mathrm{DIPT}\right]^{+}$ ( $m / z$ 491) were chosen for subsequent MKES studies because they were the most abundant of all the octahedral tartrate complexes formed and because this was the only complex studied for which the structures of 


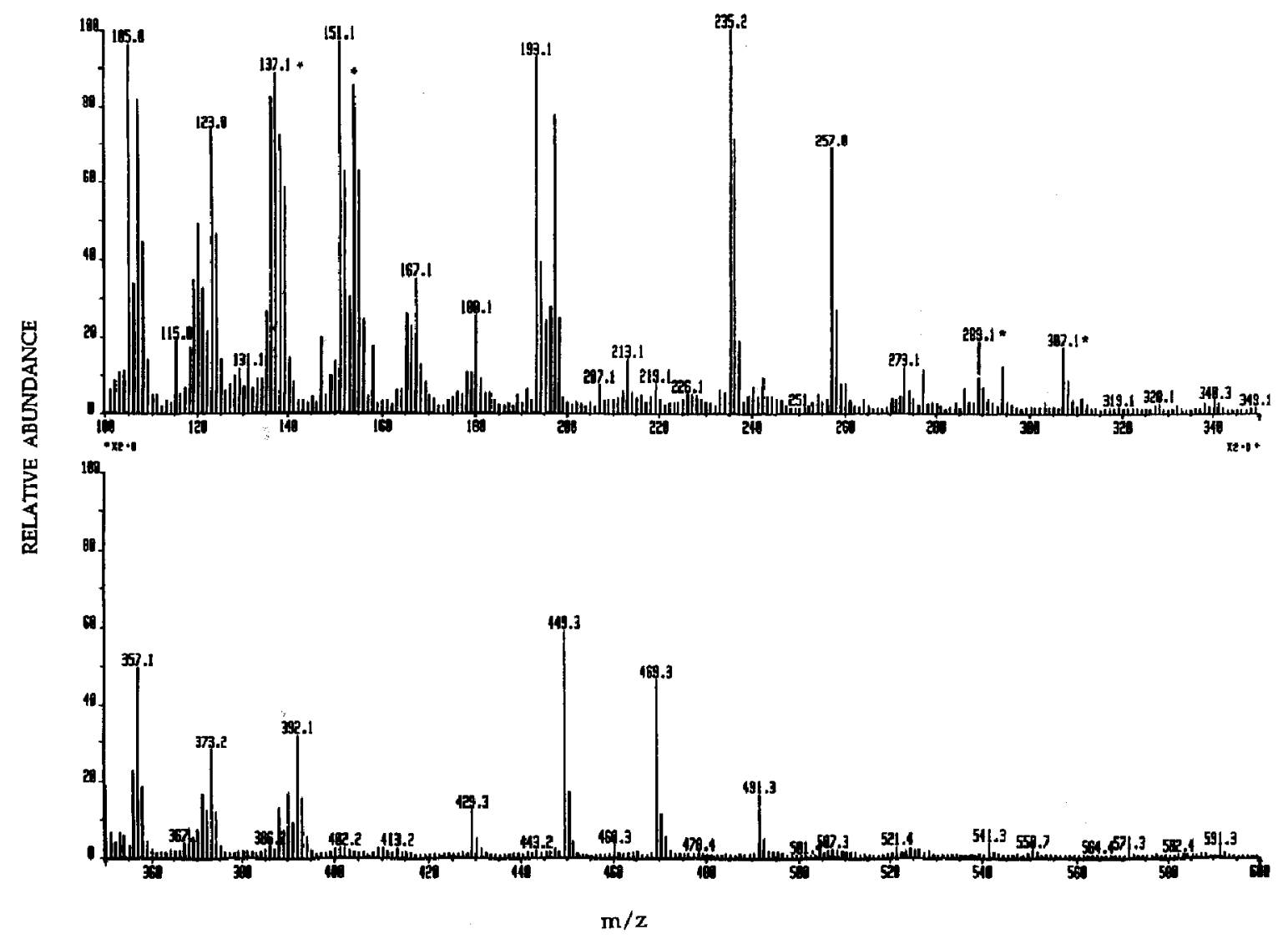

Figure 1. FAB mass spectrum of a mixture of Co(acac) $)_{3}$ SS-THB and L-DIPT with NBA matrix. The matrix ions are marked with an asterisk in the spectrum (no ions are detected beyond mass 600 ).

Table 1. Compositions of the major ions detected in the FAB mass spectrum of a mixture of Co(acac) 3 , SS-THB, and L-DIPT with NBA matrix (see Figure 1)

\begin{tabular}{|c|c|}
\hline $\begin{array}{c}\text { Mass-tu-Chyrge } \\
\text { Ratio }\end{array}$ & Composition \\
\hline 137 & Matrix \\
\hline 154 & Matrix \\
\hline 193 & [DIPT $+\mathrm{H}$-propylene] $^{+}$ \\
\hline 197 & {$\left[\mathrm{THB}-\mathrm{H}_{2} \mathrm{O}+\mathrm{H}^{+}\right.$} \\
\hline 235 & [DIPT $+\mathrm{HI}^{+}$ \\
\hline 257 & {$\left[\mathrm{Co}^{+}{ }^{3}(\mathrm{acac})_{2}\right]^{+}$and $\left[\mathrm{Na}^{+} / \mathrm{DIPT}\right]^{+}$} \\
\hline 289 & Matrix \\
\hline 307 & Matrix \\
\hline 357 & {$\left[\mathrm{Co}^{+3}\left(\mathrm{acac}_{3}+\mathrm{H}\right]^{+}\right.$} \\
\hline 372 & {$\left[\mathrm{Co}^{+2}(\mathrm{acac}) / \mathrm{THB}\right]^{+}$} \\
\hline 392 & {$\left[\mathrm{Co}^{+}{ }^{2}(\mathrm{acac}) /(\mathrm{DIPT})\right]^{+}$} \\
\hline 449 & {$[\mathrm{DIPT} / \mathrm{THB}+\mathrm{H}]^{+}$} \\
\hline 469 & {$\left[(\mathbf{D I P T})_{\mathbf{2}}+\mathbf{H}\right]^{+}$} \\
\hline 491 & $\begin{array}{c}\text { [Co }^{+3}\left(\mathrm{acac}_{2} / \mathrm{DIPT}\right]^{+} \text {and } \\
{\left[\mathrm{Na}^{+} /(\mathrm{DIPT})_{2}\right]^{+}}\end{array}$ \\
\hline
\end{tabular}

the product ions could be readily assigned. Both the DET and DBT complexes will be investigated in future studies while the DMT complexes are of little interest because the loss of $\mathrm{H}_{2} \mathrm{O}$ was the only product ion formed upon dissociation.

The ions at $m / z 491$ were allowed to undergo unimolecular decomposition in the MIKES cell and KER values were calculated as described above. Figure 2 is a partial MIKE spectrum collected for the $\left[\mathrm{Co}^{+3}(\mathrm{acac})_{2} / \mathrm{L} \text {-DIPT }\right]^{+}$complex formed in the presence of SS-THB and indicates the presence of two ions at $m / z 391$ and 393. The ion at $m / z$ 391, which represents loss of a neutral acac ligand, was too weak to measure reproducibly. However, the ion at $\mathrm{m} / \mathrm{z} 393$ (formation of this ion is discussed in detail below) was consistently abundant and very reproducible. The KER values for $\mathrm{m} / \mathrm{z} 393$ were collected in nine experiments for each of the diastereomers in the presence of RRand SS-THB and the data are shown in Table 4(I).

It is well known that the kinetic energy released in metastable ion transitions is less sensitive to internal energy, and more sensitive to ion structure [9]. Therefore, differences in the KER values would more accurately reflect differences in precursor ion structures 
Table 2. Calculated and experimental measured masses of $\left[\mathrm{Co}^{+3}\left(\mathrm{acac}_{2} / \mathrm{DIPT}\right]^{+}\right.$and $\left[\mathrm{Na}^{+} /(\mathrm{DHPT})_{2}\right]^{+}$

\begin{tabular}{|c|c|c|c|}
\hline Ion & $M_{\text {caled }}$ & $M_{\text {expt }}$ & $\Delta \mathrm{M}_{(\mathrm{m} m \mathrm{~m})}$ \\
\hline${\left[\mathrm{Co}^{+3} \text { (acacl }_{2} / \mathrm{DIPT}\right]^{+}}^{+}$ & 491.1327 & $491.1335 \pm 0.004^{a}$ & 0.8 \\
\hline$\left[\mathrm{Na}^{+} /(\mathrm{DIPT})_{2}\right]^{+}$ & 491.2104 & $491.2108 \pm 0.005$ & 0.4 \\
\hline
\end{tabular}

${ }^{a}$ Error values are standard deviation of the mean $\left(S_{x}\right)$ for four experiments.

rather than differences in precursor ion energy. The KER values reported in Table 4(I) indicate that there are statistically significant differences between the diastereomeric pairs $\mathrm{A}$ and $\mathrm{B}$. The significance of this difference becomes quite obvious when the KER of the enantiomers is measured. That is, the $\left[\mathrm{Co}^{+3}(\mathrm{acac})_{2} / \mathrm{D}-\mathrm{DIPT}\right]^{+}$complex formed in the presence of RR-THB is enantiomeric with the $\left[\mathrm{Co}^{+3}\left(\mathrm{acac}_{2}\right]\right.$ L-DIPT] $^{+}$complex formed in the presence of SS-THB.

Enantiomeric complexes, by definition, must produce the same KER value upon dissociation which is exactly what is observed as shown in Table 4(I). What is remarkable is that the KER values for pairs A and B are significantly different from one another, indicating that the precursor ion structures for these complexes must be different. That is, they must be diastereomers. The questions which the data raise are: (1) What are the structural differences between the diastereomers? (2) How important is the octahedral geometry? (3) What role does the THB play in the formation of the diastereomers? and (4) By what mechanism are the diastereomers dissociating and how does this affect the observed KER values?

\section{Effect of THB and Geometry}

In evaluating the KER results above, a question arises as to the role of THB. Since neither the RR- nor the SS-THB are included in the complex under investigation, it is important to establish if in fact the THB is affecting formation of the $\left[\mathrm{Co}^{+3}(\mathrm{acac})_{2} / \mathrm{DIPT}\right]^{+} \mathrm{di}-$ astereomer. In order to address this question, the same KER experiments were repeated for the $m / z 491$ precursor ion formed in the absence of THB. Table 4(II)

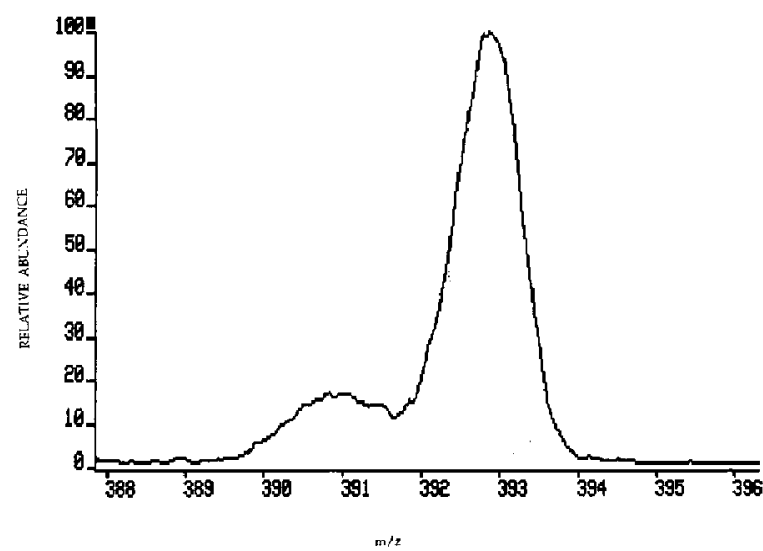

Figure 2. Partial MIKE spectrum of the $\left[\mathrm{Co}^{+3}(\mathrm{acac})_{2} / \mathrm{DIPT}\right]^{+}$ complex generated from a mixture of Co(acac) $)_{3 r}$ SS-THB and L-DIPT with NBA matrix gave two ions at $m / z 391$ and 393 (see text for compositions of the ions).

gives the KER values measured for the $m / z 393$ ion and indicates that in the absence of THB the values for the D-DIPT and L-DIPT complexes are virtually identical. This data suggests that the THB is acting as a chemical kinetic resolving agent $[11,12]$ and that it is somehow influencing how the acac ligand dissociates and/or how the DIPT ligand is added to the cobalt.

A similar effect was observed when a chiral compound, 1-amyl alcohol, was investigated by Suming et al. [6]. They reported that some $\alpha$-amino acids and $\alpha$-hydroxy acid enantiomers can be distinguished when l-amyl alcohol is present. (Others [5b] report that they were unable to reproduce these results.) Through a sequence of ion-molecule reactions, 1-amyl alcohol reacts stereospecifically with one of the enantiomers. These and our KER results clearly indicate that the presence of a chiral auxiliary compound can aid in the chiral recognition process.

In addressing the reasons for the observed chiral recognition we becarre interested as to the effects imparted by an octahedral versus tetrahedral cobalt geometry. The ion $m / z 392$ representing the tetrahedral complex $\left[\mathrm{Co}^{+2} \text { (acac)/DIPT }\right]^{+}$was mass selected and transmitted into the MIKES cell (this ion is present

Table 3. Summary of the MIKES product ions generated from the precursor $\left[\mathrm{Co}^{+3}(\mathrm{acac})_{2} \mathrm{~T}\right]^{+}$complexes (where $\mathrm{T}=\mathrm{DMT}$, DET, DIPT, or DBT)

\begin{tabular}{|c|c|c|c|c|}
\hline & $\left.\left[\mathrm{Co}^{+3} / \mathrm{acac}\right)_{2} / \mathrm{DMT}\right]^{+}$ & $\begin{array}{r}\mathrm{Co}^{+3}{\left.\text { (acac })_{2} / \mathrm{DET}\right)^{+}}_{\text {Mass-to }} \\
\text { Mas }\end{array}$ & $\begin{array}{l}{\left[\mathrm{Co}^{+3}(\text { acac })_{2} / \mathrm{DIPT}\right]^{+}} \\
\text {ge Ratio }\end{array}$ & {$\left[\mathrm{Co}^{+3}\left(\mathrm{acac}_{2} / \mathrm{DBT}\right]^{+}\right.$} \\
\hline Precursor & 437 & 463 & 491 & 519 \\
\hline Product Ions & $419\left(-\mathrm{H}_{2} \mathrm{O}\right)^{\mathrm{a}}$ & $445\left(-\mathrm{H}_{2} \mathrm{O}\right)$ & $473\left(-\mathrm{H}_{2} \mathrm{O}\right\}$ & $501\left(-\mathrm{H}_{2} \mathrm{O}\right)$ \\
\hline \multirow[t]{3}{*}{ Detected } & & 367 (Unknown) & $393(-$ acac $-H)$ & $419(-\mathrm{acac}+\mathrm{H})$ \\
\hline & & $363(-\operatorname{acac}+H)$ & 391 (acac + H) & 395 (Unknown) \\
\hline & & 345 (Unknown) & $363^{b}$ & 379 (Unknown) \\
\hline
\end{tabular}

${ }^{a}$ Compositions in parentheses represert fragment losses from the precursor.

b lon of unknown composition which results from dissociation of the $\left[\mathrm{Na}^{+}(\mathrm{DIPT})_{2}\right]^{+}$complex. 
Table 4. MIKES study of $\left[\mathrm{Co}^{+3}(\mathrm{acac})_{2} / \mathrm{DIPT}\right]^{+}$

$$
\begin{aligned}
& \text { I. In the Presence of THB } \\
& \text { Pair } A^{\mathrm{b}} \\
& \text { 1. RR-THB } / \mathrm{D} \text {-DIPT }=21.5 \pm 1.1 \mathrm{mV} \\
& \text { 2. SS-THB } / \text {-DIPT }=21.6 \pm 0.9 \mathrm{mV} \\
& \text { Pair } \mathrm{B}^{\mathrm{b}} \\
& \text { 3. RA-THB } / \text { L-DIPT }=14.1 \pm 1.2 \mathrm{mV} \\
& \text { 4. SS THB } / \text { D DIPT }=16.2 \pm 0.5 \mathrm{mV}
\end{aligned}
$$

II. Without the Presence of THB ${ }^{a b}$

$$
\begin{aligned}
& \text { 5. } \mathrm{L}-\mathrm{D} \mid \mathrm{PT}=13.3 \pm 1.8 \mathrm{mV} \\
& \text { 6. } \mathrm{D}-\mathrm{D} \mid \mathrm{PT}=13.7 \pm 0.9 \mathrm{mV}
\end{aligned}
$$

a KER values are mean values $(\bar{x})$ for nine experiments. Error values are standard deviation of the mean $\left(s_{x}\right)$.

${ }^{b}$ Pairs 1 and 2 , pairs 3 and 4 , and pairs 5 and 6 are enantiomers. The reported values are KER values of $m / 2393$ (see text for composition of $m / 2393$ ).

in the low resolution spectrum as observed in Figure 1). Upon dissociation, the ion at $m / z 350$, which represents loss of neutral propene, was detected. No other ions were detected in this spectrum. KER values for this ion are provided in Table 5(I, II). As can be seen, there were no differences in the KER values for the tetrahedral complex. This is true when the values were measured both in the presence and absence of THB.

As a second check on geometry and the effects of THB, a $\left[\mathrm{Co}^{+2} / \mathrm{DIPT} / \mathrm{THB}-\mathrm{H}\right]^{+}$complex ( $\mathrm{m} / z$ 506) was generated from $\mathrm{CoCl}_{2}$ and equimolar solutions of DII'I' and THB. The KER values were measured for the ion representing loss of neutral propanol $(\mathrm{m} / \mathrm{z} 446)$ and the data shown in Table 6. Once again, no differences in the KER values were observed between diastereomeric tetrahedral complexes. This data also indicates that although THB needs to be present to observe chiral recognition for the octahedral complexes, it in itself has no effect as part of a tetrahedral complex.

The above experiments suggest that at least two requirements must be fulfilled in order to observe chiral recognition in this system: (1) The geometry of the cobalt complex needs to be octahedral, and (2) the presence of THB, which acts as a chemical kinetic

Table 5. MIKES study of $\left[\mathrm{Co}^{+2} \text { (acac)/DIPT }\right]^{+}$

\begin{tabular}{l}
\hline \hline I. In the Presence of THB $^{\mathrm{a}}$ \\
Pair A \\
1. RR-THB $/$ D-DIPT $=42.1 \pm 1.2 \mathrm{mV}$ \\
2. SS-THB $/$-DIPT $=41.9 \pm 0.4 \mathrm{mV}$ \\
Pair $B^{\mathrm{b}}$ \\
3. RR-THB $/$-DIPT $=43.1 \pm 1.1 \mathrm{mV}$ \\
4. SS-THB $/$ D-DIPT $=40.9 \pm 0.8 \mathrm{mV}$ \\
II. Without the Presence of THB \\
5. L-DIPT $=40.4 \pm 0.6 \mathrm{mV}^{\mathrm{b}}$ \\
6. D-DIPT $=41.3 \pm 0.6 \mathrm{mV}$
\end{tabular}

\footnotetext{
aER values are mean values $(\bar{x})$ for nine experiments. Error values are standard deviation of the mean $\left(s_{x}\right)$.

bairs 1 and 2 , pairs 3 and 4 , and pairs 5 and 6 are enantiomers.

The reported values are KER values of $m / 2350$ (loss of propene).
}

resolving agent, must be present. Although there are differences in oxidation states of the cobalt in the tetrahedral $(+2)$ versus the octahedral $(+3)$ geometry, there is no evidence that this is a contributing factor in these particular systems.

\section{Gas Phase Structures and Mechanism of Dissociation}

Deuterium labeling studies were conducted on the $\left[\mathrm{Co}^{+3}(\mathrm{acac})_{2} / \mathrm{DIPT}\right]^{+}$complexes in an effort to address the dissociation pathways involved in the losses of both the neutral acac ligand to produce the product ion at $m / z 391$ and the loss of 98 AMU which produced the product ion at $m / z$ 393. The hydrogens on both hydroxyl groups of DIPT and THB as well as the hydroxylic hydrogens of the nitrobenzyl alcohol matrix were exchanged with deuterium using $\mathrm{D}_{2} \mathrm{O}$ according to our previously published methodology [10]. The ion at $m / z \quad 491$ representing the $\left.\left[\mathrm{Co}^{+3} \text { (acac) }\right)_{2} / \mathrm{DIPT}\right]^{+}$ complex thus shifted by two mass units to $m / z 493$. This ion was then transmitted to the MIKES cell and the spectrum recorded. The product ions at $m / z 391$ and 393 observed in Figure 2 shifted to $m / z 392$ and 395 , respectively. The data suggest that the loss of the neutral acac ligand occurs via an intramolecular hydrogen (or deuterium in this case) transfer from the DIPT ligand to the acac ligand, resulting in the loss of 101 mass units from the labeled compound. However, the ion at $m / z 395$ still represents a loss of 98 AMU which indicates that the acac ligand must lose one of its hydrogens to the complex. The structure representing a two-electron reduction of $\mathrm{Co}^{+3}$ followed by protonation of the acac ligand to produce $\left[\mathrm{C}^{+1}(\mathrm{acacH}) / \mathrm{DTPT}\right]^{+}$is eliminated since the deuterium analog would have produced an ion at $m / z$ 394 which was not observed in the spectrum of the labeled compound. A proposed mechanism for this 98 AMU loss is illustrated in Scheme I and is consistent with the data. Hydride transfer from one of the acac methyl groups produces a cobalt hydride and a zwitterionic intermediate which can then dissociate via pathway A (loss of acetyl cyclopropyl ketone) or $\mathbf{B}$ (loss of keto dihydrofuran). Since this mechanism involves a hydride $\left(\mathrm{H}^{-}\right)$shift, the oxidation state of cobalt remains +3 in the structure represented by the ion at $m / z$ 393. It is also conceivable that the proposed

Table 6. MIKES study of $\left[\mathrm{Co}^{+2} / \mathrm{DIPT} / \mathrm{THB}-\mathrm{H}\right]^{+}$

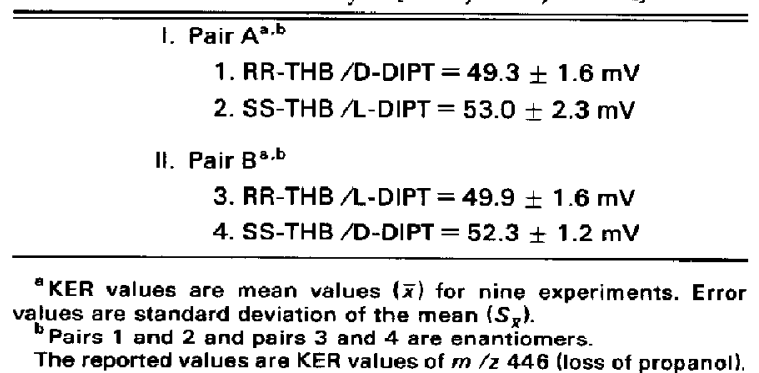




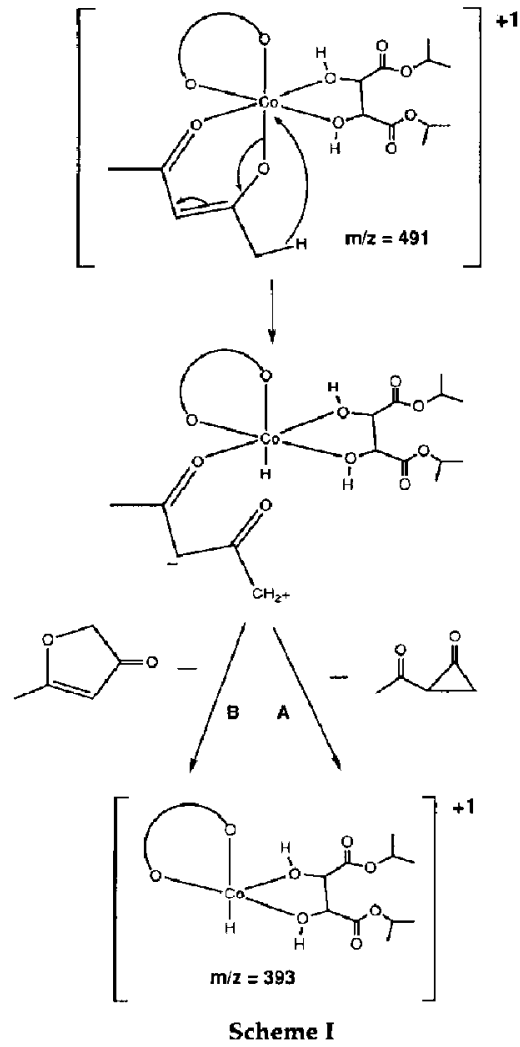

hydride transfer mechanism can be followed by molecular hydrogen elimination thereby generating the ion at $m / z 391$, or in the case of the labeling study, $m / z$ 392 (loss of HD). Unfortunately we cannot unambiguously determine if the ion at $\mathrm{m} / z 391$ is generated via the hydrogen elimination or if in fact it is a direct loss of the neutral acac ligand from the precursor as described above.

Hydride transfer reactions in metal coordinated systems have been reported by this group [13] and others [14] and thus have precedence in the literature. Similarly, this type of reaction has been proposed as an agostic bond interaction $[15,16]$ in which the $\mathrm{C}-\mathrm{H}$ bond of the methyl group on the organic ligand acts as a ligand to a transition metal center forming a covalent $\mathrm{C}-\mathrm{H} \rightarrow \mathrm{Co}$ system with subsequent donation of two electrons to the metal. This interaction weakens the $\mathrm{C}-\mathrm{H}$ bond while strengthening the $\mathrm{H} \rightarrow$ Co interaction and the organic ligand is then lost as indicated in Scheme I.

Having accurately measured the differences in the KER experiments and assuming that these differences reflect a difference in the precursor ion structure, the question arises as to what the structural differences are and how the THB affects these structures. Tris(chelate)complexes such as $\mathrm{Co}\left(\mathrm{acac}_{3}\right.$ lack a plane of symmetry and therefore can exist as $\Delta$ and $\Lambda$ enantiomers or as a racemic mixture of the two [17].
Thus, one possible explanation is that the THB selectively complexes to one enantiomer of the $\mathrm{Co}(\mathrm{acac})_{3}$ racemate thus leaving the other enantiomer free to complex with the tartrate. For example, RR-THB might coordinate preferentially to the $\Delta$ form of Co(acac) ${ }_{3}$ thus resolving the racemate sufficiently to allow the Dand L- DIPT to coordinate only to the $\Lambda$ form. The reverse would then hold true for the SS-THB. Fundamentally, these diastereomers $(\Delta D$ and $\Lambda \mathrm{L}$ versus $\Delta \mathrm{L}$ and $\Lambda D$ ) are by definition energetically different. This in itself would explain the differences in the KER values.

The other possibility is that the THB again selectively complexes to one enantiomer of the Co(acac) ${ }_{3}$, but now in this case, this short lived intermediate $\left[\mathrm{Co}^{+3}(\mathrm{acac})_{2} / \mathrm{THB}\right]^{+}$reacts with tartrate in such a manner as to replace the THB with the tartrate ligand as shown in Scheme II. Cobalt substitution reactions which have been studied in solution have shown that substitution can occur by a dissociative pathway. The five-coordinate structures $(5,6$, and 7$)$ shown in Scheme II are not stereochemically rigid and can undergo Berry or turnstyle pseudorotation [18] thus scrambling the ligands.

Future experiments involve repetition of the KER measurements using the resolved enantiomers of Co(acac) $)_{3}$. Such an experiment will help us to understand this system in greater detail. For example, resolution of the Co(acac) ${ }_{3}$ by THB need not be complete in order to observe the differences reported in this paper. If either of the above postulations is correct, the enantiomerically pure cobalt complex should produce larger differences in the KER values between diastereomers. We will also be examining the effects of other chiral auxiliaries with the goal of ultimately being able to assign the absolute stereochemistry of unknown compounds.

\section{Conclusions}

Kinelic energy release measurements of the product ion of an octahedral cobalt complex, $\left[\mathrm{Co}^{+3}\left(\mathrm{acac}_{2} / \mathrm{D}-\right.\right.$

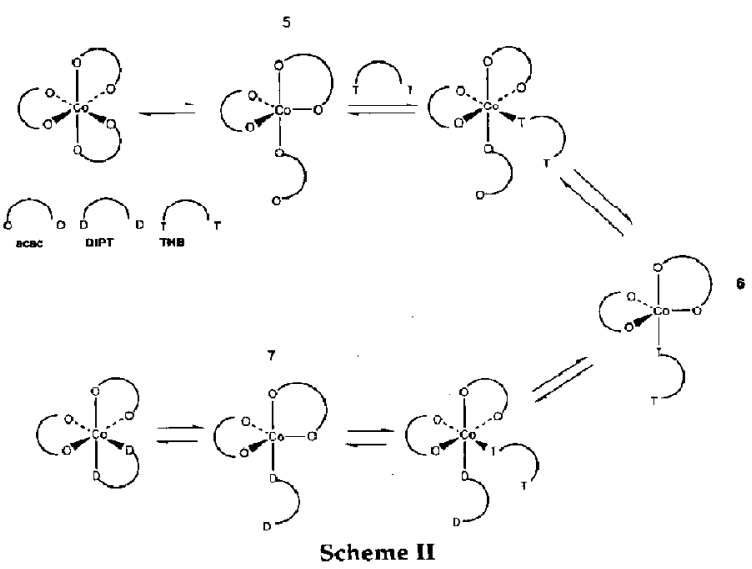


or $\mathrm{L}-\mathrm{DIPT}^{+}$, indicate that these diastereomers can be distinguished in the gas phase. It is postulated that THB acts as a kinetic resolving agent in this particular system and preferentially coordinates to one enantiomer of $\mathrm{Co}(\mathrm{acac})_{3}$, thereby leaving the other enantiomer free to react with the alkyl tartrate ester. The data clearly indicate that the precursor ion must also be octahedral in geometry in order to observe differences in the KER values for the diastereomers. A proposed method of dissociation for these complexes is via a hydride transfer from the acetylacetonate ligand to the metal center with subsequent loss of neutral organic species.

\section{Acknowledgments}

The authors thank Dr. Gretchen Hofmeister and Dr. Susan Kegley for preliminary work on this project. The authors also thank both Mr. Marc Reilly and Mr. Geoff Bott for assistance with setting up the MIKES cell and subsequent maintenance. Preliminary reports on this project were presented at the 40th Annual ASMS Conference on Mass Spectrometry and Allied Topics, 1992.

\section{References}

1. Eiceman, G. A.; Clement, R. E.; Hill, H. H. Jr. Anal. Chem. 1992, 64, 170R

2. Pirkle, W. H.; Pochapsky, T. C. Chem. Rev. 1989, 89, 347.

3. Fales, H. M.; Wright, G. J. J. Am. Chem. Soc. 1977, 99, 2339.
4. Mandelbaum, A. Mass Spec. Reo. 1983, 2, 223.

5. (a) Winkler, F. J.; Stahl, D.; Maquin, F. Tet. Lett. 1986, 27, 335;

(b) Baldwin, M. A.; Howell, S. A.; Welham, K. J. Biomed. Environ. Mass Spec. 1988, 16, 357.

6. Suming, $H_{. ;}$Yaozu, C.; Longfei, J.; Shuman, X. Org. Mass Spec. 1986, 21, 7 .

7. Hofmeister, G.; Leary, J. A. Org, Mass Spec. 1991, 26, 811.

8. Sawada, M.; Okumura, Y.; Shizuma, M.; Takai, Y.; Hidaka, Y.; Yamada, H.; Tanaka, T.; Kaneda, T.; Hirose, K.; Misumi, S.; Takahashi, S. J. Am. Chem. Soc. 1993, 115, 7381.

9. Cooks, R. G.; Beynon, J. H.; Caprioli, R. M.; Lester, G. R. Metastable Ions, Elsevier, 1973.

10. Hofmeister, G.; Zhou, Ž.; Leary, J. A. J. Am. Chem. Soc. 1991, $113,5964$.

11. Sharpless, K. B.; Rossiter, B. E.; Katsuki, T. S. I. Am Chem. Soc. $1981,103,464$

12. Juaristi, E. Introduction to Stereachemical and Conformational Analysis, John Wiley \& Sons, Inc., 1991.

13. Zheng, Y. J.; Staempfli, A,; Leary, J. A. J. Am. Soc. Mass. Spectrom., 1993, 4, 943.

14. (a) Zheng, Y. J.; Merz, K. M. Jr.; Fauber, G. K. Protein Engineering, 1993, 6, 479; (b) Ramchander, S.; Feather, M. S. Arch. Biochem. Biophys. 1977, 178, 576.

15. Calhorda, M. J.; Martinho Simoes, J. A. Organometallics 1987, $6,1188$.

16. Brookhart, M.; Green, M. L. H. J. Organumet. Chem. 1983, 250, 395.

17. Huheey, J. E. Inorganic Chemistry, Harper \& Row: New York, 3rd edn., 1983.

18. Wang, P.; Agrafiotis, D. K,; Streitwieser, A.; von Rague Schleyer, P. Chem. Comm. 1990, 3, 201. 